\title{
A dynamic equation for a published Sitka spruce site-dependent height-age model
}

\author{
by Chris J. Cieszewski ${ }^{1}$ and Gordon D. Nigh ${ }^{2}$
}

\begin{abstract}
We present a new Sitka spruce (Picea sitchensis (Bong.) Carr) site-dependent height-age model that is based on a dynamic site equation simulating previously published height-age curves for various productivity sites. The new model is an improvement over the previous model because it uses any arbitrary height-age pair to directly predict a height at another age, instead of using a fixed base-age site index as the older model does. Consequently, it can also be used directly to compute height at any age from site index or site index from any height and age instead of relying on numerical solutions for site index computations. The model predicts the same heights for any site as the original fixed base-age model and has the same desirable properties of polymorphism, inflection point, variable asymptotes, logical behaviour, theoretical basis, parsimony, and improved extrapolation. The model is offered as an algebraic improvement only, and therefore it was calibrated on pseudo-data generated from the old model's predictions rather than on real data. The proposed equation mimics the old model better than the other dynamic equations tested in this study, which is illustrated using examples with the Chapman-Richards function. Analysis with the real data might offer further improvements to the model predictions.
\end{abstract}

Keywords: Base-age invariance, height-age model, model properties, nonlinear regression, Sitka spruce, site index

Nous présentons un nouveau modèle selon la station et la hauteur en fonction de l'âge pour l'épinette de Sitka (Picea sitchensis (Bong.) Carr) qui repose sur une équation de la dynamique de la station reproduisant les courbes déjà publiées de la productivité de différentes stations. Le nouveau modèle représente une amélioration par rapport au modèle précédent parce qu'il utilise toutes paires arbitraires hauteur-âge pour prédire directement la hauteur pour un autre âge, plutôt que d'utiliser un indice fixe de station en fonction de l'âge comme le font les autres modèles. En conséquence, il peut être utilisé directement pour établir la hauteur à tout âge à partir de l'indice de la station ou l'indice de la station à partir de la hauteur et de l'âge plutôt que de compter sur les solutions numériques pour établir l'indice de la station. Le modèle prédit les mêmes hauteurs pour toute station comme le modèle original basé sur un âge donné et présente les mêmes propriétés recherchées comme le polymorphisme, le point d'inflexion, les asymptotes variables, le comportement logique, le fondement théorique, la parcimonie et l'extrapolation rendue plus facile. Le modèle est offert comme une amélioration algébrique seulement, et en conséquence, il a été calibré à partir de pseudo-données générées des prédictions du modèle antérieur plutôt que sur des données réelles. L'équation proposée simule le modèle antérieur mieux que les autres équations dynamiques testées au cours de cette étude qui est illustrée au moyen d'exemples de la fonction Chapman-Richard. L'analyse au moyen de données réelles pourrait offrir de plus amples améliorations des modèles de prédiction.

Mots-clés: invariance en fonction de l'âge, modèle hauteur-âge, propriétés des modèles, régression non-linéaire, épinette de Sitka, indice de station

\section{Introduction}

Site-dependent height-age models are used for predictions or estimations of future or past heights. Most commonly, the predictions from these models are based on current measurements of heights at different ages, even though the models are typically formulated in such a way that it is first necessary to obtain a fixed base-age site index, and then calculate the height at the desired age. This is the case for the Sitka spruce (Picea sitchensis (Bong.) Carr) height-age model (Nigh 1997), which requires a site index of base-age 50 years at breast height to make predictions. Since most trees are not 50 years old, site index is usually estimated from measurements of available heights and ages. This makes using the height-age model a two-step process. Site index is first estimated using numerical procedures, and then height at the desired age is estimated from the site index. Occasionally, when there are no trees on a given site, the prediction of expected height growth can be based on site index values estimated from other environmental

\footnotetext{
${ }^{1}$ Assistant Professor, Fiber Supply Assessment, W.D. Warnell School of Forest Resources, University of Georgia, Athens GA 30602 USA. E-mail biomat@uga.edu

${ }^{2}$ Biometrician, Growth and Yield, B.C. Ministry of Forests, Research Branch, P.O. Box 9519, Stn. Prov. Govt., Victoria, B.C. V8W 9C2. E-mail: Gordon.Nigh@gems2.gov.bc.ca
}

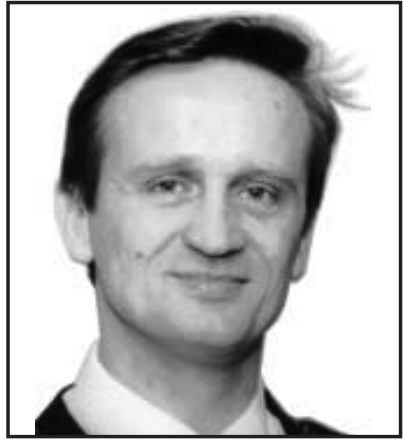

Chris J. Cieszewski

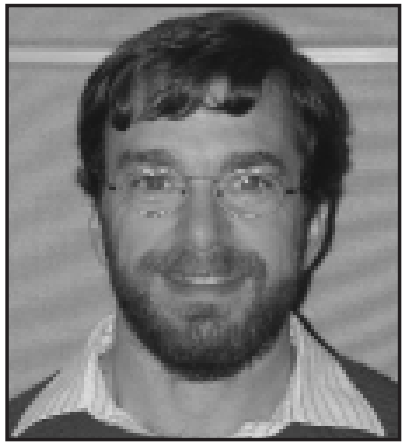

Gordon D. Nigh variables, such as soil nutrient and moisture regimes, precipitation, or vegetation growing on the site.

Other methods of height projections were also suggested in the literature although not widely accepted. For example, Zeide (1993a, 1978, 1994) advocated the use of two-point-principle modelling instead of the one-point-principle upon which site index models are based. However, the two-point-principle approach has neither been completed analytically (it is only offered in a form of tabular algorithms), nor is it as useful as a site index model because it requires twice as many input variables such as two known heights at two different known ages, or two site indexes at two different base ages. This article deals 
only with the notion of using a single height as the control variable in site-dependent height-age models.

Height-age models are also used for determination of site quality, which is conventionally quantified as a site index, that is, a height at a given fixed base-age, e.g., 50 years. The main reason why height of some specified portion of the largest trees in a stand is used for site quality classification is that it is the most stable stand characteristic that remains unaffected by a wide range of stand densities. The site-dependent height-age models are usually formulated in forms of either dynamic or static equations. The dynamic site equations have the general form:

$$
\mathrm{Y}=\mathrm{f}\left(\mathrm{t}, \mathrm{t}_{0}, \mathrm{Y}_{0}, \beta\right)
$$

where $\mathrm{Y}$ is the function value at $\mathrm{t}, \mathrm{Y}_{0}$ is the point of reference defined as the function value at $t_{0}$, and $\beta$ is the vector of model parameters. Thus, they define both height-growth and site index models as special cases of the same equation-a property desirable in many applications because few stands will be measured at ages equal to the base age. They use variable base ages in such a way that the selection of a base age has no effect on predictions. This property is called base-age invariance (Bailey and Clutter 1974). Despite an abundance of literature (e.g., Grosenbaugh 1965; Ratkowsky 1983, 1986; Zeide 1993b, 1996) on equations describing individual curves (i.e., $\mathrm{Y}=\mathrm{f}(\mathrm{t})$ ), there is relatively little literature available on dynamic site models. Furthermore, out of some few hundred publications on site-dependent models, only a couple dozen use dynamic equations.

Static site equations have the general form of: $Y=f(t, S, \beta)$, where $Y$ is the height at age $t, \beta$ is the vector of model parameters, and $\mathrm{S}$ is a fixed-base-age (of say, 50 years) site index. These types of models are, by far, the most common forms of site equations used for modelling self-referencing height-age relationships in even-age stands.

Sitka spruce is an important timber species in the coastal regions of $\mathrm{BC}$ where it occupies some $17 \%$ of the timber harvesting land base (British Columbia Ministry of Forests 2000). Nigh (1997) reviews several models for Sitka spruce in $\mathrm{BC}$ and presents a new model for this species based on the constrained loglogistic equation (Goudie 1984). This model offered a number of improvements over the other reviewed models, including improved extrapolation properties, biologically sound curve shapes, and a number of other desirable characteristics.

However, the model offered by Nigh (1997) does not have other desirable properties, such as a defined origin at age zero, base-age invariance, a dynamic algebraic form and an analytical solution for the fixed base age site index. We present here a further improvement of the Sitka spruce model for BC generating the same shapes of curves as proposed by Nigh (1997), but based on an algebraic formulation that also has the other desirable properties such as a defined origin at age zero, baseage invariance, a dynamic algebraic form and an analytical solution for the fixed-base-age site index. No additional analyses on real data were conducted and the parameter values for the proposed new model form are derived solely from pseudo-data based on Nigh's (1997) model. Yet, it is quite evident that the proposed model form has a number of advantages over the original model that makes the utility of the new model more valuable and its implementation more practical.

\section{Data}

The original data for the model described in Nigh (1997) came from 40 sample plots that were established in Sitka spruce stands on the Queen Charlotte Islands. Pseudo-data were generated for decadal values of ages between 0 and 110 years and for site index values of 15 to $40 \mathrm{~m}$ in steps of $5 \mathrm{~m}$, which were the approximate ranges represented in the original data used in the development of the model described in Nigh (1997). The model (Nigh 1997) used to generate pseudo-data is:

$$
\mathrm{H}=1.3+(\mathrm{SI}-1.3) \times \frac{1+\mathrm{e}^{\alpha-\delta^{\prime} \times \ln (49.5)-\gamma \times \ln (\mathrm{SI}-1.3)}}{1+\mathrm{e}^{\alpha-\delta^{\prime} \times \ln (\mathrm{BHA}-0.5)-\gamma \times \ln (\mathrm{SI}-1.3)}}
$$

where $\mathrm{H}$ is height (m), SI is site index (m), BHA is breast height age (years), $\mathrm{e}$ is the base of natural logarithms, $\ln$ is the natural logarithm, $\alpha=8.947, \delta^{\prime}=1.357$, and $\gamma=1.013$.

\section{Methods}

Cieszewski (2001) presents a general four-parameter baseage invariant (Bailey and Clutter 1974) dynamic equation. Variants of this model correspond to different assumptions about the model parameter values. He suggests that the following threeparameter version of the model is the most likely to define a useful and biologically sound relationship (equation 21 in Cieszewski 2001):

$$
\mathrm{Y}=\mathrm{Y}_{0} \times \frac{\mathrm{t}^{\delta}\left(\mathrm{t}_{0}^{\delta} \times \mathrm{R}+\kappa\right)}{\mathrm{t}_{0}^{\delta}\left(\mathrm{t}^{\delta} \times \mathrm{R}+\kappa\right)}
$$

where $\mathrm{R}=\mathrm{Z}_{0}+\sqrt{\mathrm{Z}_{0}^{2}+\frac{2 \times \kappa \times \mathrm{Y}_{0}}{t_{0}^{\delta}}}$ and $\mathrm{Z}_{0}=\mathrm{Y}_{0}-\eta$, $\mathrm{Y}$ is height (m) at breast height age $\mathrm{t}$ (years), and $\mathrm{Y}_{0}$ is height (m) at breast height age $\mathrm{t}_{0}$ (years). This total age model can be converted to a breast height age model with a half-year age correction for bias by subtracting 1.3 from $\mathrm{Y}$ and $\mathrm{Y}_{0}$ and 0.5 from $t$ and $\mathrm{t}_{0}$. Nonlinear least squares regression was used to fit model (3) to the pseudo-data.

To provide a relative evaluation criteria for the degree of model fit to the pseudo-data we also fitted the model to three other dynamic equations, based on the Chapman-Richards function solutions for its different parameters (Clutter et al. 1983, Bailey 1980). These included the anamorphic form based on the solution for the asymptote parameter:

$$
Y=Y_{0}\left(\frac{1-\mathrm{e}^{-b \times t}}{1-\mathrm{e}^{-b \times t_{0}}}\right)^{c}
$$

the polymorphic form based the solution for the time scale parameter:

$$
Y=a\left(1-\left(1-\left(\frac{y_{0}}{a}\right)^{1 / c}\right)^{t / t_{0}}\right)^{c},
$$

and the polymorphic form based on the solution for the exponent parameter: 
Table 1. Results of the fitting of model (3) to pseudo-data generated from model (2)

\begin{tabular}{|c|c|c|c|c|}
\hline \multirow[b]{2}{*}{ Parameter } & \multirow[b]{2}{*}{ Estimate } & \multirow{2}{*}{$\begin{array}{c}\text { Standard } \\
\text { Error }\end{array}$} & \multicolumn{2}{|c|}{$95 \%$ confidence interval } \\
\hline & & & Lower & Upper \\
\hline K & 14269 & 2.8709 & 14263 & 14274 \\
\hline$\delta$ & 1.3570 & 0.000035233 & 1.3570 & 1.35 \\
\hline$\eta$ & 37.782 & 0.0049690 & 37.772 & 37.792 \\
\hline
\end{tabular}

$$
Y=a\left(\frac{y_{0}}{a}\right)^{\frac{\ln \left(1-\mathrm{e}^{-b \times t}\right)}{\ln \left(1-\mathrm{e}^{-b \times t_{0}}\right)} .}
$$

\section{Results}

Table 1 contains the results of the analysis. This table shows the parameter estimates, their standard errors, and their 95\% confidence intervals. Model (2) and the fitted model (3) are virtually identical. The mean squared error (MSE) for model (3) is essentially zero (0.0007), with the residuals ranging from a low of $-0.0017 \mathrm{~m}$ to high of $0.0029 \mathrm{~m}$, and having a mean of $-0.000000001 \mathrm{~m}$. The MSE of model (3) should be considered only as a measure of model (3)'s similarity to model (2). The relevant MSE for model (2) was 4.0 after reversing the transformation used for the model fitting (Nigh 1997). The near-perfect fit of model (3) to the pseudo-data is also demonstrated in Fig. 1A and 2, which both show the data points being closely overlaid on the model curves. The fits of the three other dynamic equations were much worse (Fig. $1 \mathrm{~B}$ C, and D), with MSE values being several orders of magnitude greater, i.e., $0.8,1.5$, and 2.0 for models 4,5 , and 6 , respectively. From the comparison of the different models it is clear that the use of pseudo-data is appropriate for the analysis of model forms, while fitting models to such data without natural variation and errors is anything but error-free.

The base-age invariance of the new model is illustrated in Table 2 whereby all the series are identical. The numbers in this table were derived in the following way. First, the new model
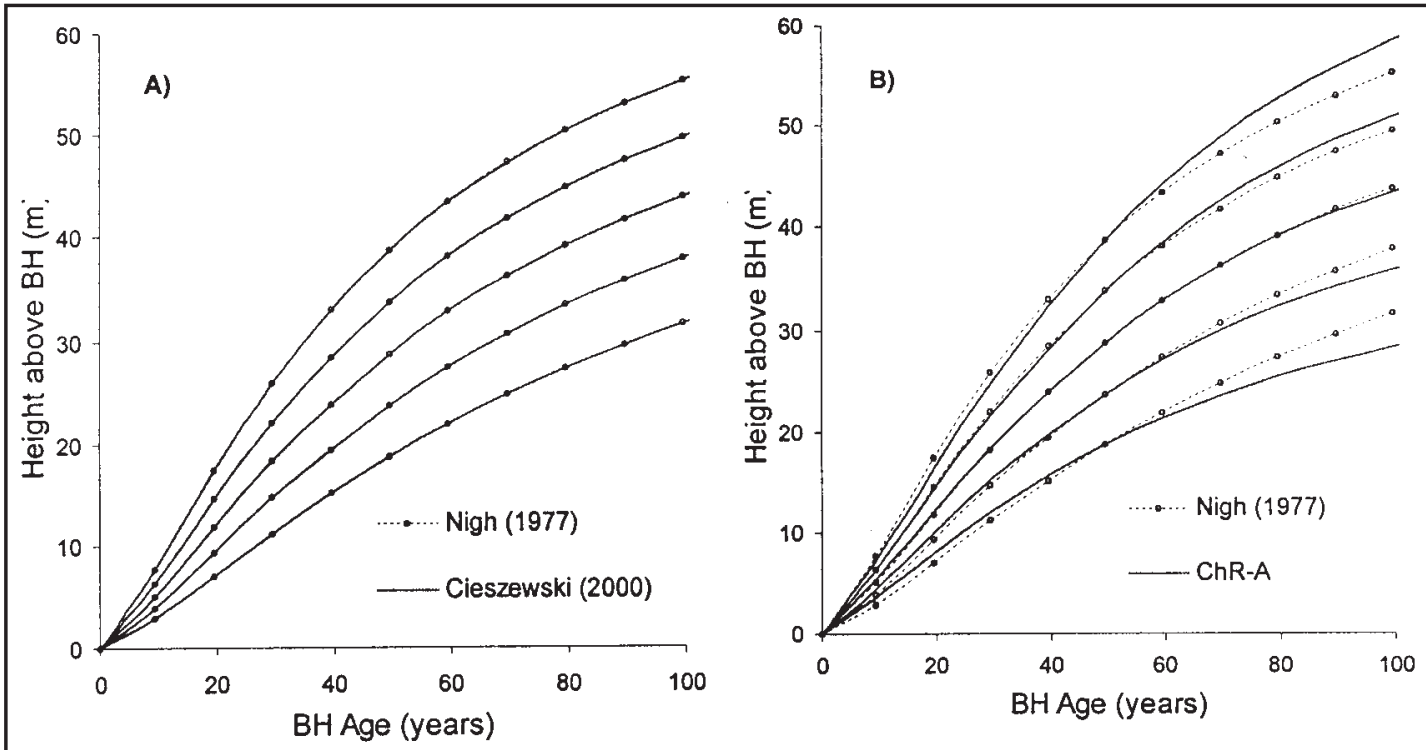

Fig. 1. Height-age curves generated by the Nigh (1997) model (symbols) and models fitted to its pseudo-data (solid lines) based on equations: A) 3; B) 4 ; C) 5 ; and D) 6 .
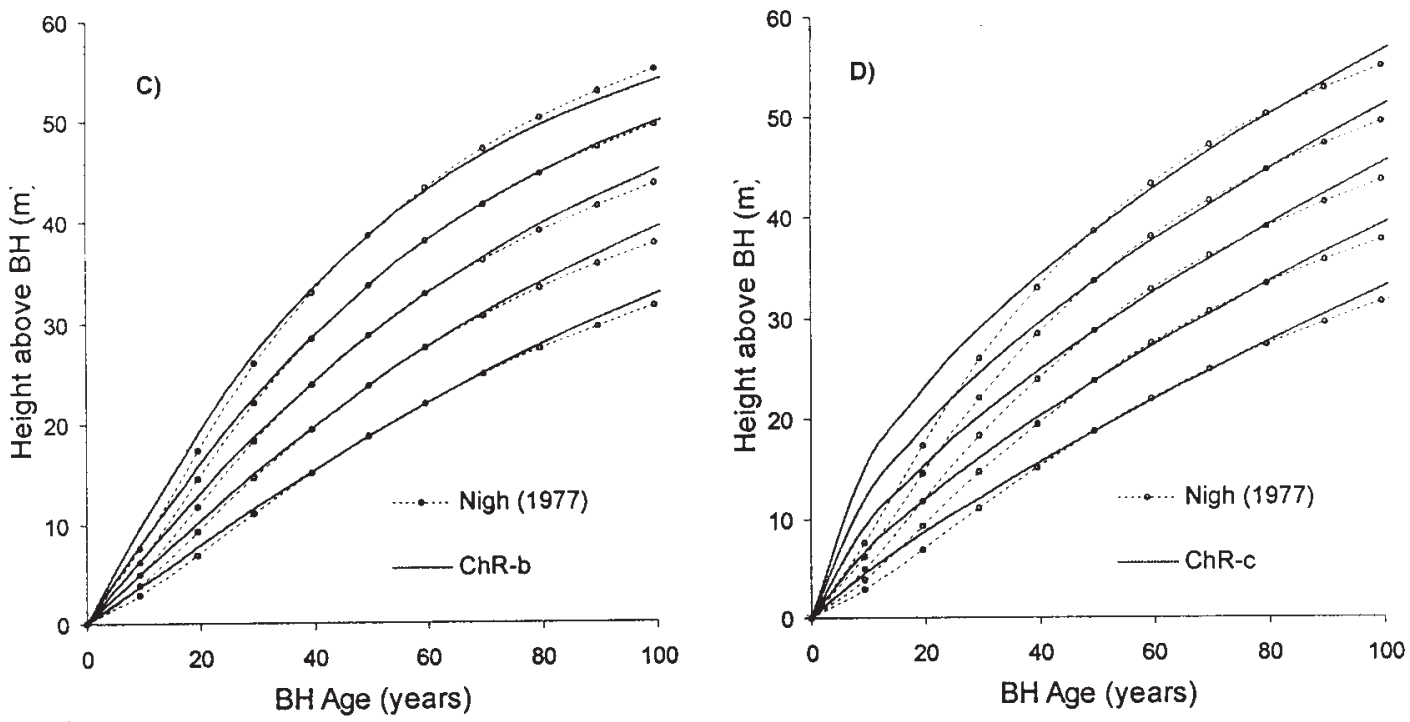


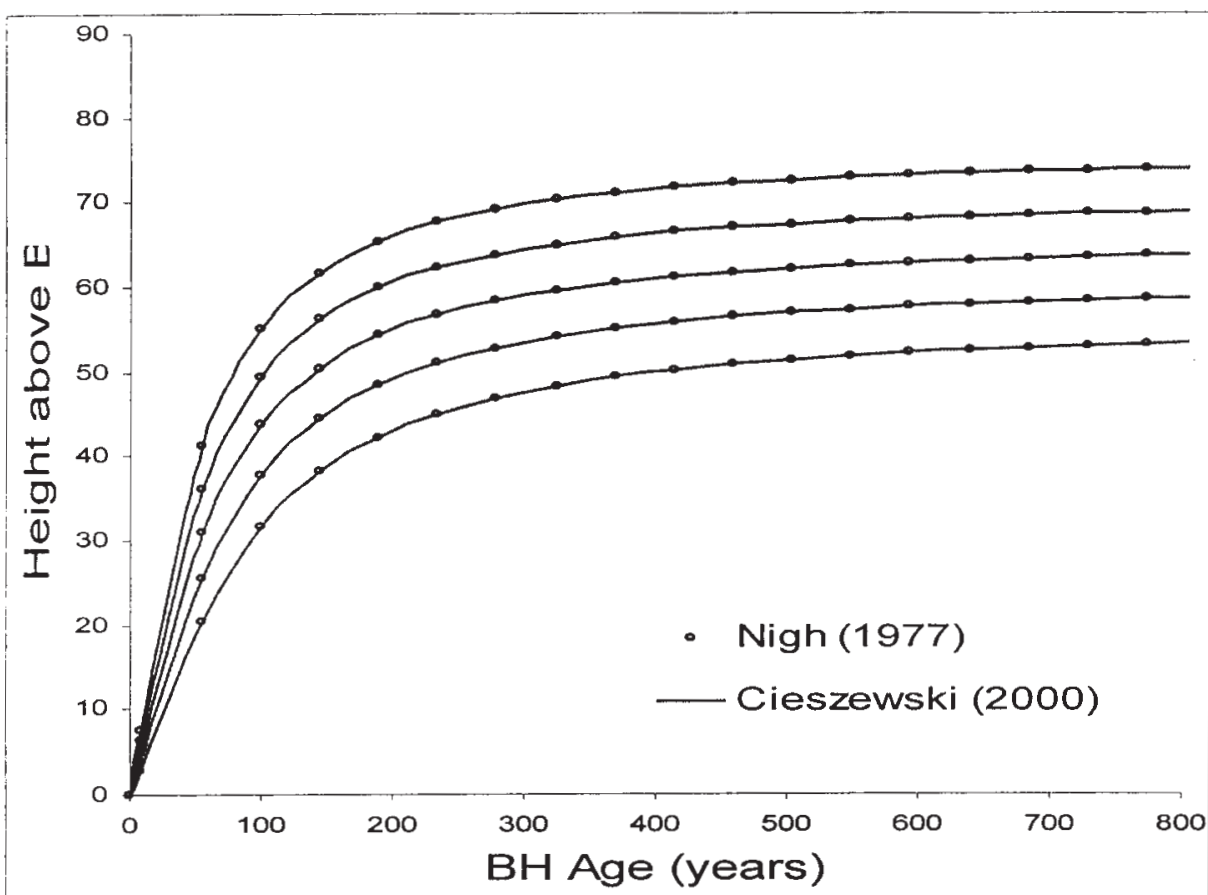

Fig. 2. Height-age curves generated by the models described in a) Nigh (1997) - the curves defined by symbols; and b) Cieszewski (2001) with parameters presented in this paper - solid lines.

Table 2. Height predictions from model (7) with base ages of 20,50 , and 100 and equivalent site indices showing the base-age invariance property of the model

\begin{tabular}{lccccccccccc}
\hline \multirow{2}{*}{$\begin{array}{l}\text { Base } \\
\text { Age (years) }\end{array}$} & $\begin{array}{c}\text { Site } \\
\text { Index (m) }\end{array}$ & $\mathbf{1 0}$ & $\mathbf{2 0}$ & $\mathbf{3 0}$ & $\mathbf{4 0}$ & $\mathbf{5 0}$ & $\mathbf{6 0}$ & $\mathbf{7 0}$ & $\mathbf{8 0}$ & $\mathbf{9 0}$ & $\mathbf{1 0 0}$ \\
\hline 20 & 10.60 & 5.17 & 10.60 & 15.92 & 20.75 & 25.00 & 28.69 & 31.88 & 34.64 & 37.03 & 39.11 \\
50 & 25.00 & 5.17 & 10.60 & 15.92 & 20.75 & 25.00 & 28.69 & 31.88 & 34.64 & 37.03 & 39.11 \\
100 & 39.11 & 5.17 & 10.60 & 15.92 & 20.75 & 25.00 & 28.69 & 31.88 & 34.64 & 37.03 & 39.11 \\
20 & 15.79 & 7.56 & 15.79 & 23.30 & 29.69 & 35.00 & 39.40 & 43.04 & 46.09 & 48.66 & 50.84 \\
50 & 35.00 & 7.56 & 15.79 & 23.30 & 29.69 & 35.00 & 39.40 & 43.04 & 46.09 & 48.66 & 50.84 \\
100 & 50.84 & 7.56 & 15.79 & 23.30 & 29.69 & 35.00 & 39.40 & 43.04 & 46.09 & 48.66 & 50.84 \\
\hline
\end{tabular}

with base-age 50 years was used to generate height series for site index values of 25 and 35 . Then, the heights from ages 20 and 100 were used as site indices with base ages of 20 and 100 years, respectively, to generate new height-age series, which are identical to the series generated using base-age 50 .

\section{Discussion}

Nigh (1997) found equation (2) to be suitable for modelling Sitka spruce height-age relationships in B.C. This model has many desirable properties, such as polymorphism, an inflection point, asymptotes, logical behavior, theoretical basis, parsimony, and reasonable extrapolated height estimates (Nigh 1997). Model (3) and model (2) are virtually identical in predictions. They also share the polymorphism, inflection, asymptotic, logical behavior, and extrapolation properties. Both models only have three parameters, so they are also parsimonious. As well, model (3) includes as a special case the biologically based model in Cieszewski and Bella (1989) so it can also be classified as having a biological basis. In addition to these properties, model (3) is an algebraic improvement over model (2) in that, unlike model (2), it i) is defined at age equal zero, ii) uses variable base ages, iii) represents both a height and site index model in one common equation, and iv) is base-age invari- ant, which are other desirable properties for site index models Therefore, model (3) has more desirable properties than model (2) without compromising any other properties and, the most importantly, height estimates. Model 3 in its final form and fitted to the pseudo-data for Sitka Spruce is:

$$
\begin{aligned}
& Y=Y_{0} \times \frac{t^{1.3570}\left(t_{0}^{1.3570} \times R+14269\right)}{t_{0}^{1.3570}\left(t^{1.3570} \times R+14269\right)} \\
& \text { where } R=Z_{0}+\sqrt{Z_{0}^{2} \frac{2 \times 14269 \times Y_{0}}{t_{0}^{1.3570}}}
\end{aligned}
$$

and $Z_{0}=Y_{0}-37.782$,

where: $\mathrm{t}_{0}$ is an arbitrary reference age (less the age bias correction, e.g., 0.5); $\mathrm{Y}_{0}$ is any height at age $\mathrm{t}_{0}$ (less $1.3 \mathrm{~m}$ breast height correction); $\mathrm{t}$ is an arbitrary prediction age; and $\mathrm{Y}$ is height (m) at breast height age $\mathrm{t}$ (less $1.3 \mathrm{~m}$ breast height correction). Appendix 1 contains SAS code for this equation. 
Equation (2) can be algebraically approximated from equation (3) by letting $\delta=\delta^{\prime}, \eta=\kappa \div 49.5^{\delta^{\prime}}=38.553 \times(\mathrm{SI}-1.3)^{-0.013}$, $\mathrm{Y}_{0}=\mathrm{SI}-1.3, \mathrm{t}_{0}=49.5, \mathrm{Y}=\mathrm{H}-1.3$, and $\mathrm{t}=\mathrm{BHA}-0.5$. In model (3), $\delta=1.3570, \eta=37.782$, and $\kappa=14269$. Since $(\text { SI }-1.3)^{-0.013}$ is close to 1 regardless of the value of SI, the values for $\eta$ and $\kappa$ in model (7) are very close to the values for those same two parameters in model (2), and the value for $\delta$ is exactly the same. Therefore, not only are the two models close graphically-they are also close algebraically.

The presented study was based on an assumption that the original model represents the data well and possibly better than the offered dynamic equation would if it were fitted to the real data. Given this, we wanted to answer the question "What is the minimum cost of using the dynamic equation anyway for its algebraic advantages, such as direct use of height at any ages and readily available site index solutions?" This meant that we had to concentrate on the special case of the geometric similarities between the two algebraically different formulations, which could only be accomplished through the analysis of pseudo-data generated from the original model; this special case might not be observable with the real data because the optimal fit of the two equations may result in different curve patterns. On the other hand, this study demonstrated that there would be no practical appreciable cost of using the dynamic equation instead of the static equation (i.e., only $0.0007 \mathrm{~m}$ ), while its algebraic advantages in the model implementation are quite substantial.

The assumption of this study about the superior representation of the data by the original model was not tested, and therefore, the dynamic model (3) also provides potential for an improved fit to the data by re-calibrating the model with stem analysis data. This was not done in this case because the fit of model (2) was deemed to be acceptable. However, should additional stem analysis data become available, model (3) would be a good candidate for fitting and comparing to other models.

\section{Conclusion}

The dynamic site model presented here provides the same height estimates as the currently used model for Sitka spruce, and it shares the same desirable properties. Moreover, the dynamic site model also has the additional desirable properties of being defined at age equal zero, using height directly at any age instead of a fixed-base-age site index, and being base-age invariant. Thus, we believe that this model would be a good candidate for developing new height-age models for Sitka spruce and other species.

\section{References}

Bailey, R.L. 1980. The Potential of Weibull-type Functions as Flexible Growth Curves: Discussion. Can. J. For. Res. 10: 117-118. Bailey, R.L. and Clutter, J.L. 1974. Base-age invariant polymorphic site curves. For. Sci. 20: 155-159.

British Columbia Ministry of Forests. 2000. Queen Charlotte Timber Supply Area Analysis Report. B.C. Min. For., Timber Supply Br., Victoria, B.C.
Cieszewski, C.J. 2001. Three methods of deriving advanced dynamic site equations demonstrated on inland Douglas-fir site curves. Can. J. For. Res. 31: 165-173.

Cieszewski, C.J. and I.E. Bella. 1989. Polymorphic height and site index curves for lodgepole pine in Alberta Can. J. For. Res. 19: 1151-1160.

Clutter, J.L., J.C. Fortson, L.V. Pienaar, G.H. Brister and R.L.

Bailey. 1983. Timber management. John Wiley and Sons, Inc. New York. 333 p.

Goudie, J.W. 1984. Height growth and site index curves for lodgepole pine and white spruce and interim managed stand yield tables for lodgepole pine in British Columbia. B.C. Min. For. Res. Br. Unpubl. Rep.

Grosenbaugh, L.R. 1965. Generalization and reparameterization of some sigmoid and other nonlinear functions. Biometrics 21: 708-714.

Nigh, G.D. 1997. A Sitka spruce height-age model with improved extrapolation properties. For. Chron. 73(3): 363-369.

Ratkowsky, D.A. 1983. Nonlinear regression modeling: a unified practical approach. Marcel Dekker, New York.

Ratkowsky, D.A. 1986. Choosing near-linear parameters in the four-parameter logistic model for radioligand and related assays. Biometrics 42: 575-582.

Zeide, B. 1978. Standardization of growth curves. J. For. 76: 289-292.

Zeide, B. 1993a. A parsimonious number of growth curves. North. J. Appl. For. 10: 132-136.

Zeide, B. 1993b. Analysis of growth equations. For. Sci. 39: 594-616.

Zeide, B. 1994. To construct or not to construct more site index curves? West. J. Appl. For. 9: 37-40.

Zeide, B. 1996. Investigating parameters of growth equations. Can. J. For. Res. 26: 1980-1990.

\section{Appendix 1.}

SAS code for model (7).

data Ss; * create a data set containing height estimates;

t $0=50-0.5 ; *$ Set the base age to be 50 years at breast height minus the age bias correction;

$\mathrm{Y} 0=30.00-1.3 ; *$ specify the site index corresponding to the base age minus the breast height;

do $t=10$ to 100 by 10 ; * select a range of ages for height estimates;

$/ *$ Estimate heights for specified base age, site index, and ages adding the breast height $*$ /

$\mathrm{Y}=1.3+\mathrm{Y} 0 *$

$(\mathrm{t} * * 1.357 *(\mathrm{t} 0 * * 1.357 *(\mathrm{Y} 0-37.782+\operatorname{sqrt}((\mathrm{Y} 0-37.782) * * 2+$

$28538 * \mathrm{Y} 0 / \mathrm{t} 0 * * 1.357))$

$+14269)) /$

$(\mathrm{t} 0 * * 1.357 *((\mathrm{t}-.5) * * 1.357 *(\mathrm{Y} 0-37.782+\operatorname{sqrt}((\mathrm{Y} 0-37.782) * * 2$

$+28538 * \mathrm{Y} 0 / \mathrm{t} 0 * * 1.357))$

$+14269)$ )

output; * output the height estimates;

end; 